J. Lake Sci.(湖泊科学), 2009, 21(1): 128-134

http://www.jlakes.org. E-mail: jlakes@niglas.ac.cn

(C2009 by Journal of Lake Sciences

\title{
西藏纳木错水深分布及现代湖沼学特征初步分析*
}

\author{
王君波 ${ }^{1}$, 朱立平 ${ }^{1}$, Gerhard Daut $^{2}$, 鞠建廷 ${ }^{3}$, 林 $\quad$ 晓 ${ }^{1,4}$, 汪 勇 $^{1}$, 甄晓林 ${ }^{1}$ \\ (1: 中国科学院青藏高原研究所, 北京 100085) \\ (2: Institut für Geographie, Friedrich-Schiller-Universität, Jena, Germany) \\ (3: 中国科学杂志社, 北京 100717) \\ (4: 中国地质大学, 武汉 430074)
}

摘 要: 2005-2007 年对西藏最大的湖泊一一纳木错进行了三次综合考察, 获得了大量的基础数据和研究材料. 本文简要报道 纳木错水深测量及其现代湖沼学特征的初步结果. 等深线图显示纳木错是一个高海拔的深水湖, 湖盆中部是一个水深超过 $90 \mathrm{~m}$ 底部较为平坦的盆地. 考察中发现湖泊西北部出现了两个小岛, 而 $1970 \mathrm{~s}$ 考察时仍为半岛, 因而水深数据提供了近 30 年 来纳木错湖面上升的有力证据. 现场水质测量在 16 个站点进行, 覆盖了除东部湖区以外的大部分湖面范围, 结果显示表层水 的温度、 $\mathrm{pH}$ 、溶解氧、电导率和环境光的平均值分别为 $11.63^{\circ} \mathrm{C} 、 9.13 、 7.93 \mathrm{mg} / \mathrm{L} 、 1839 \mu \mathrm{S} / \mathrm{cm} 、 2582 \mu \mathrm{mol} /\left(\mathrm{s} \cdot \mathrm{m}^{2}\right)$. 根据湖水 特征的垂直变化, 较深水域的湖水显示了明显的分层特征: 上层湖水从表层到约 $18-20 \mathrm{~m}$, 水质参数均一, 温度较高, 光照充 足; 中间层范围约为 20-60m, 是一个明显的温跃层; 底层水性质也很稳定, 水温很低几乎没有光线到达, 形成了寒冷黑暗的 深水区.

关键词: 水深测量; 湖面上升; 湖沼学特征; 温跃层; 纳木错; 青藏高原

\section{Bathymetric survey and modern limnological parameters of Nam Co, central Tibet}

\author{
WANG Junbo ${ }^{1}$, ZHU Liping ${ }^{1}$, DAUT Gerhard ${ }^{2}$, JU Jianting ${ }^{3}$, LIN Xiao ${ }^{1,4}$, WANG Yong ${ }^{1} \&$ ZHEN Xiaolin ${ }^{1}$ \\ (1: Institute of Tibetan Plateau Research, Chinese Academy of Sciences, Beijing 100085, P.R.China) \\ (2: Institut für Geographie, Friedrich-Schiller-Universität, Jena, Germany) \\ (3: Science in China Press, Beijing 100717, P.R.China) \\ (4: China University of Geosciences, Wuhan 430074, P.R.China)
}

Abstract: Comprehensive field investigations had been conducted for three times on Nam Co, central Tibet during 2005-2007. Here we presented the preliminary results focusing on bathymetric survey and water quality measurements. Isobathic map showed that Nam Co is a high altitude deep lake where a flat and large basin lies in the central part with more than 90m water depth. Data on water depth in northwestern bank areas of Nam Co provided unquestionable evidence for water level rising in the recent three decades due to the formation of two small islands which were peninsulas in 1970s. Water quality at 16 stations covering more than half of the whole lake showed that temperature, $\mathrm{pH}$, dissolved oxygen, conductivity and photosynthetically active radiation (PAR) of surface water was averagely $11.63^{\circ} \mathrm{C}, 9.13,7.93 \mathrm{mg} / \mathrm{L}, 1839 \mu \mathrm{S} / \mathrm{cm}$ and $2582 \mu \mathrm{mol} /\left(\mathrm{s} \cdot \mathrm{m}^{2}\right)$, respectively. According to the vertical variations of water quality parameters, water column in relatively deep lake areas of Nam Co could be divided into three layers with distinctly various features. The first layer was from surface to about $18 \sim 20 \mathrm{~m}$ depth in which parameters was stable with higher temperature and abundant sunlight; the second layer ranged about $20 \mathrm{~m}$ to $60 \mathrm{~m}$ where thermocline developed; and the bottommost layer was characterized as also very stable with low temperature and no light, forming a cold and dark underwater world.

Keywords: Bathymetric survey; water level rising; limnological parameters; Thermocline; Nam Co; Tibetan Plateau

* 国家自然科学基金项目(40701194)、国家重点基础研究发展计划项目(2005CB422002)和中国科学院青藏高原研究所青年 人才领域前沿专项经费联合资助. 2008-07-30 收稿; 2008-10-20 收修改稿. 王君波, 男, 1977 年生，博士，副研究员; E-mail: wangjb@itpcas.ac.cn. 
随着全球变化研究的不断发展, 湖泊及其沉积物越来越受到各学科研究者的重视, 成为环境变化、 生态系统、工业污染等研究的重要载体. 青藏高原作为地球上海拔最高、数量最多、面积最大的高原湖 泊分布区 ${ }^{[1]}$, 被认为是进行湖泊学和古湖泊学研究的理想区域. 事实上, 过去 30 年以来在青藏高原已经 开展了大量的湖泊沉积与环境变化的研究 $[2-3]$.

作为古湖泊学研究的基础性工作, 湖泊的野外考察与监测非常重要, 内容包括测深、现代湖沼学特 征测量以及其他与湖泊本身相联系的工作. 然而, 对于青藏高原地区的湖泊来说, 与古湖泊学的研究相 比, 综合性的湖泊考察还显得较为缺乏. 20 世纪 70 年代, 中国科学院相关单位对青海湖进行了系统的综 合的科学考察, 获得了大量的基础资料 ${ }^{[4]}$, 此后在青藏高原上也报道了一些湖泊的考察报告 ${ }^{[5-11]}$. 近年来, 对青海湖湖底构造及沉积物分布的地球物理勘探研究大大加深了对湖泊考察的认识, 提高了研究水平 ${ }^{[12]}$; 而对藏南地区的普莫雍错进行的多次连续考察从地形地貌、湖泊测深、湖面变化、水质测量、湖泊营养 状况、水化学特征、水生生物分布等不同方面进行了综合研究, 获得了对湖泊现代状况的全面认识 ${ }^{[13-15]}$.

纳木错位于西藏自治区中南部，是西藏第一大湖，也是青藏高原面积第二大的湖泊. 由于其独特的 自然地理条件, 纳木错成为进行古环境、区域生态系统和湖泊现代过程研究的理想地点, 目前已开展了 一些环境变化方面的研究 ${ }^{[16-20]}$. 而遥感影像研究显示近 30 年来随着区域气温升高、冰川融水增加导致纳

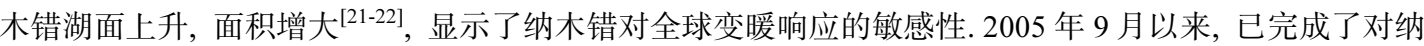
木错的 3 次综合科学考察, 本文主要报道纳木错湖泊测深及湖水理化性质测量的初步结果.

\section{1 研究区概况}

纳木错位于青藏高原的中南部地区, 地理位置为 $90^{\circ} 16^{\prime}-91^{\circ} 03^{\prime} \mathrm{E}$ 和 $30^{\circ} 30^{\prime}-30^{\circ} 55^{\prime} \mathrm{N}$ (图 1), 湖泊南部 是念青唐古拉山脉. 纳木错是第三纪喜马拉雅构造运动抝陷而成, 湖面海拔 $4718 \mathrm{~m}^{[5]}$, 最近的研究显示纳 木错在晚第四纪时期面积非常大甚至与周围的一些小湖相互连通 ${ }^{[23]}$. 全新世以来随着气候的变化, 纳木 错面积逐渐缩小 ${ }^{[5]}$, 但是过去 30 年以来湖泊面积又有所扩张, 现在纳木错面积约为 $1980 \mathrm{~km}^{2[21]}$. 纳木错 流域面积为 $10610 \mathrm{~km}^{2}$, 补给系数为 5.53 .

纳木错流域是一个封闭湖盆, 主要补给来源为大气降水和冰川融水. 纳木错周边共有超过 60 条河流 进入湖泊，这些河流大部分分布在湖泊的西部和南部，最大的几条补给河流发源于念青唐古拉山脉，在 湖泊西南部注人纳木错, 而湖泊南部多是呈辫梳状排列的小河流 ${ }^{[5]}$. 根据 1979 年考察数据, 纳木错表层 水的矿化度平均为 $1.78 \mathrm{~g} / \mathrm{L}$, 根据 $\mathrm{Hammer}^{[24]}$ 的分类标准, 纳木错属于微咸水湖, 但湖水和河水的水化学 资料显示纳木错正逐步趋向咸化 ${ }^{[5]}$.

\section{2 方法}

\section{1 测深}

由于纳木错面积巨大, 为提高湖泊考察的效率而又能最大程度的覆盖全湖, 2005-2007年分别在纳木 错东北岸、南岸中间及西北岸建立考察营地(图 1), 对纳木错不同湖区进行考察.

使用了两种仪器对湖泊进行深度测量, 一种是广州中海达测绘仪器有限公司生产的 HD-27 数字单频 测深仪; 另一种是德国 Innomar Technologie GmbH 生产的沉积物回声测量仪(Sediment Echo Sounder SES-96). 两种测深仪具有相同的测量原理, 带有 GPS 接收器, 都能记录瞬时的水深值(精确到 $0.01 \mathrm{~m}$ )和 地理位置(精确到 $0.001 \mathrm{~s}$ ). 两种仪器的声速都设定为 $1460 \mathrm{~m} / \mathrm{s}$. 事实上, 湖水中的声速在不同水深处也有 一定的差异 ${ }^{[25-26]}$, 由于在纳木错没有声速变化的资料, 因而没有对测深仪声速进行校正，即在所有水深 都使用相同的声速值.

\section{2 水质测量}

水质测量所用仪器为美国哈西公司生产的 Hydrolab DS5 型多参数水质监测仪, 带有温度、 $\mathrm{pH}$ 、电 导率、溶解氧、环境光(又称为光合有效辐射 PAR)等传感器以及利用水压测量的水深数据.

利用两种方法在湖面上进行测量. 一种是单点测量法，即利用仪器自带的水深测量探头所确定的水 深值将仪器置于某一特定深度的位置处, 待仪器稳定后记录各指标的数值, 通常测量点垂直间隔为 $5 \mathrm{~m}$ 
左右; 另一种方式是连续测量法, 即将仪器缓慢连续地放人水中直至测量点的最深处, 在此期间仪器自 动记录湖水的各个参数的数值, 记录间隔设定为每秒记录一次.

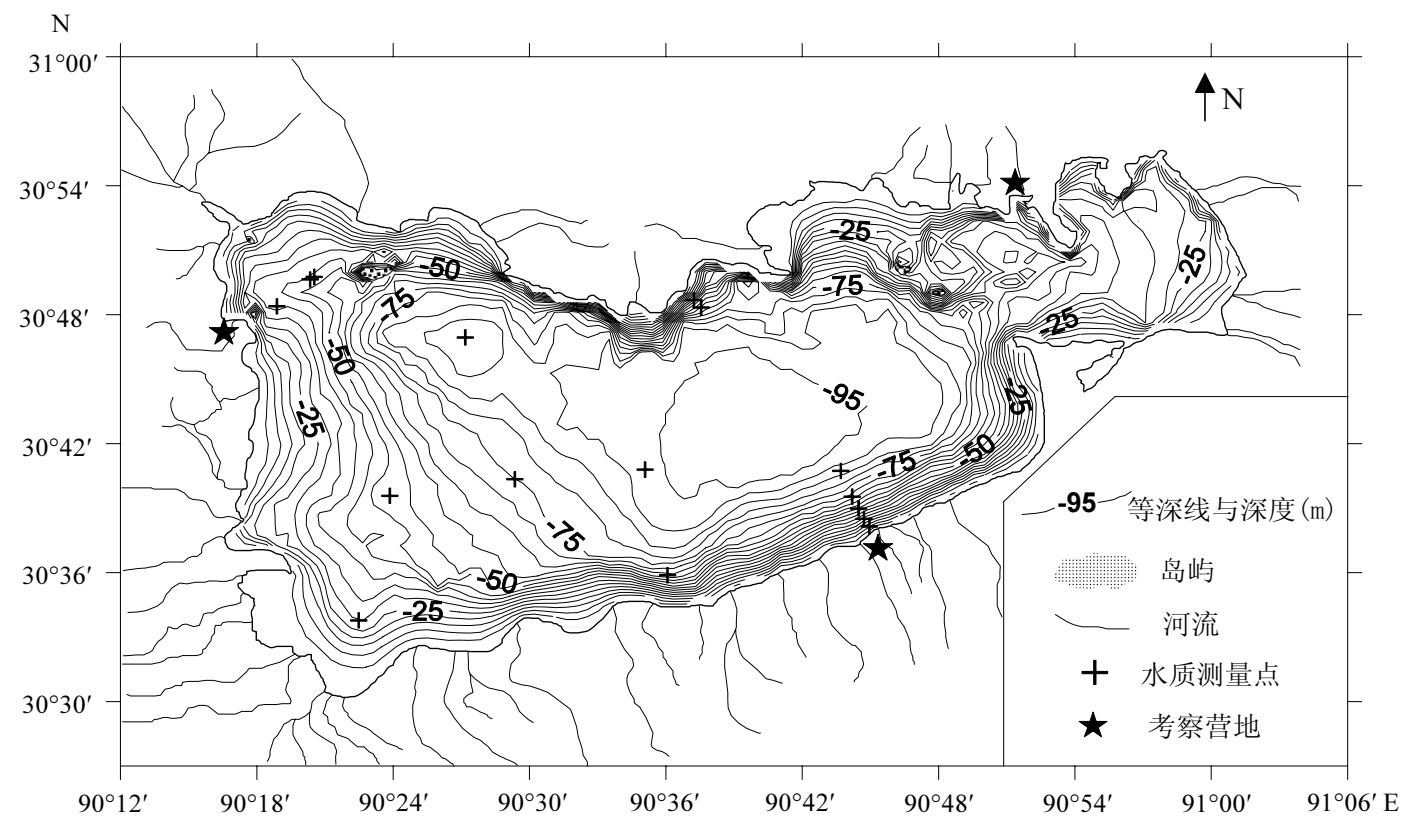

图 1 纳木错等深线图及水质测量点分布

Fig.1 Isobath of Nam Co and water quality survey sites

\section{3 结果与讨论}

\section{1 两种测深仪器测量结果对比}

水深测量利用 2 种仪器完成, 因而得到 2 套水深数据, 为了将两套数据合并使用必须进行数据的可 比较性验证. 在两套数据中选取了距离非常相接近的 60 对数据进行对比, 假设 2 个仪器所连接的 GPS 接 收器间的误差可以忽略不计, 每对数据的经纬度差值都限制在 0.00001 度以内, 大概相当于水平距离相 差不超过 $1.4 \mathrm{~m}$, 根据所选出的这 60 对数据的经纬度, 计算得出其水平距离的差值范围为 $0.19-1.40 \mathrm{~m}$, 平 均为 $0.84 \mathrm{~m}$, 因而可以认为每对数据都基本代表同一个位置, 据此可以比较 2 种仪器所记录的水深数据. 所选出的 60 对数据的水深范围为 2.03-95.75m(图 2), 基本可以代表所有水深的数据.

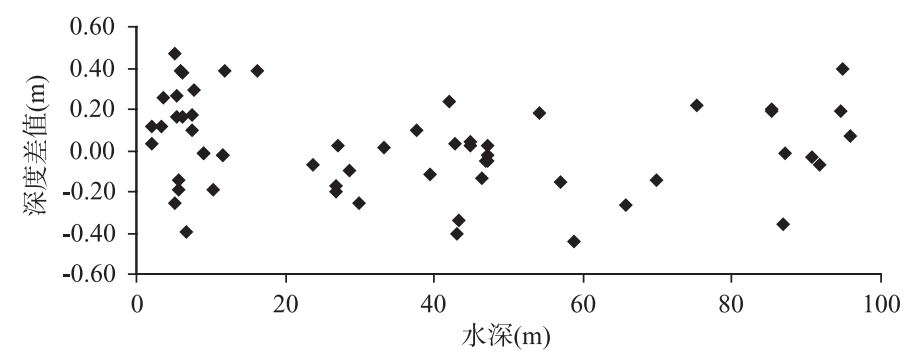

图 22 种测深仪测量结果的对比

Fig.2 Comparison of depth results measured by two bathymetric equipments

图 2 显示了这 60 对水深数据的差值与水深变化的关系, 结果表明随深度的变化两种仪器测量的同一 地点的深度差值基本上是一种随机分布，除个别点外基本都分布于 $\pm 0.40 \mathrm{~m}$ 之间，甚至大部分都在 $\pm 0.20 \mathrm{~m}$ 
范围内. 这 60 对数据差值的算术平均值为 $0.01 \mathrm{~m}$, 因此可以认为在同一地点两种仪器测量的结果相差很 小, 两套数据具有很好的可比性, 因而可以合并用来描述全湖的水深分布状况.

\section{2 纳木错水下地形分布特征}

3 次考察中湖泊测深路线覆盖了大部分湖区，基本可以代表全湖的状况. 经过初步处理后，共得到可 用的水深数据 305721 个, 其中利用 SES-96 仪器得到 190027 个, 利用 HD-27 仪器得到 115694 个.

纳木错等深线如图 1 所示, 从等深线可以发现纳木错水下地形分布的一些特点. 首先, 纳木错最深 处超过 $95 \mathrm{~m}$ 并且在湖区中部地区是一个大而平坦的湖底平原, 整体水深都超过 $90 \mathrm{~m}$. 其次, 纳木错湖底 地形分布特征在不同方向显示了明显的差异，南北两侧的水下坡度非常大甚至有一些水下悬崖出现; 而 东西两侧的坡度则较为平缓，具有水下冲积扇的特点，这些水下地形分布特征与湖面以上各方向的地形 具有很好的一致性，纳木错南北两岸都是山地，特别是南岸的念青唐古拉山脉; 而东西则是河流冲积平 原. 整个纳木错湖盆以及湖泊本身都是一个近东西向分布的狭长的底部平缓的盆地.

从考察结果来看, 纳木错中共有 5 个岛屿, 其中东北部有 2 个, 西北部有 3 个. 根据 1970 年代的考 察资料 ${ }^{[5]}$, 图 1 中所示的 5 个岛屿当时只有 3 个是岛屿, 西北部湖泊边缘的两个小岛还是与陆地相连的半 岛. 从本次湖泊测深实际情况来看, 这两个岛屿已经和湖岸完全分离, 说明与 1970 年代相比纳木错湖面 有所上升, 湖泊测深数据为近 30 年来纳木错湖面上升提供了直接证据.

\section{3 纳木错表层水理化特征}

水质测量总共在不同水深的 16 个站点进行, 覆盖了湖泊的大部分区域, 特别是中西部地区(图 1). 为 了比较纳木错湖水的水平变化特征, 首先对所有站点表层水的理化性质进行对比(表略). 可以发现表层 水的温度变化范围为 $10.99-12.58^{\circ} \mathrm{C}$, 不同站点不同测量时间的结果稍有差异, 其平均值为 $11.63^{\circ} \mathrm{C} ; \mathrm{pH}$ 变 化范围为 8.04-9.85, 显示了较大的差异, 其平均值为 9.13, 说明湖水为弱碱性, 纳木错湖水的 $\mathrm{pH}$ 值与相 邻的色林错非常相近 ${ }^{[11]}$, 而与 1979 年考察时所测的 9.4-9.5 的 $\mathrm{pH}$ 相比, 此次测量得到的 $\mathrm{pH}$ 似乎有降低 的趋势, 但不排除两次测量间不同仪器所带来的误差; 溶解氧的平均浓度为 $7.93 \mathrm{mg} / \mathrm{L}$, 饱和度为 $100.9 \%$, 比色林错的溶解氧水平稍高 ${ }^{[11]}$. 电导率在各站点间差异较小, 平均值为 $1839 \mu \mathrm{S} / \mathrm{cm}$, 大约是藏南普莫雍 错的 4 倍左右 ${ }^{[13]}$. 作为湖水透光性的表征, 环境光参数(PAR)在不同站点出现了明显的差异, 这可能主要 源于测量时的天气状况以及测量时间的不同, PAR 在天气晴好的中午最大值可达 $4631 \mu \mathrm{mol} /\left(\mathrm{s} \cdot \mathrm{m}^{2}\right)$, 所有 站点平均值为 $2582 \mu \mathrm{mol} /\left(\mathrm{s} \cdot \mathrm{m}^{2}\right)$.

从表层水性质的空间差异来看, 温度、 $\mathrm{pH}$ 和溶解氧 3 个参数没有显示出明显的规律，而电导率则显 示出西部湖区(2007 年数据)比中部湖区(2006 年数据)稍高的特点，可能是由于西部湖区靠近补给河流因 而湖水中含有更多溶质的原因. PAR 显示了与电导率相反的特征，即在湖泊西边比中部低，从各站点的位 置来看, 大部分 PAR 的低值都位于河口附近, 说明西部湖水的清澈度不如湖泊中部, 这也可能是入湖河 流的影响造成的.

\section{4 水质剖面的垂向变化特征}

所有站点的水质测量都是从表层到最深处, 得到了水质参数的垂直剖面变化特征. 在一定深度范围 内的水质剖面显示了相似的变化特征. 图 3 是 2 个站点的测量结果, 其中第一个是利用单点测量法, 测量 时间是 2006 年 9 月 19 日 $15: 04$, 站点位置为 $30^{\circ} 40.733^{\prime} \mathrm{N}, 90^{\circ} 43.700^{\prime} \mathrm{E}$ (图 3a); 而另一个是利用连续测量 法, 测量时间是 2007 年 8 月 18 日 12: 22, 站点位置为 $30^{\circ} 46.986^{\prime} \mathrm{N}, 90^{\circ} 27.291^{\prime} \mathrm{E}$ (图 3b).

湖水温度从表层开始都较为稳定, 变化范围为 $11-12^{\circ} \mathrm{C}$, 随深度增加温度逐渐下降, 并出现明显的温 跃层然后温度逐渐下降到 $4^{\circ} \mathrm{C}$ 左右, 之后随深度增加温度基本维持不变. 温跃层开始出现的深度在各个 站点具有差异，分布于 10-28m 之间，但没有显示出与站点水深和地理位置的关系. 温跃层的厚度大约为 25-30m，在不同剖面间未见明显差异. 纳木错水温的垂向变化特征与藏南普莫雍错非常相似 ${ }^{[14]}$.

纳木错湖水 $\mathrm{pH}$ 的垂向变化非常小, 所有测量结果的变化范围为 7.52-10.28, 图 3 所示的 2 个剖面的 $\mathrm{pH}$ 垂向变化趋势非常相似，在中等深度的区域内都有一个低值区，但这一低值区所在的水深并不相同， $\mathrm{pH}$ 最大值一般出现在表层, 然后随深度增加 $\mathrm{pH}$ 逐渐降低并在 $30-50 \mathrm{~m}$ 深度处达到最低值, 然后又有缓 慢增加的趋势. 
溶解氧显示了整体上随深度增加而减小的趋势, 但在 20-30m 水深处有一个反向增加的阶段. 从整 个剖面变化来看, 溶解氧的实际浓度变化并不大(图 $3 \mathrm{~b}$ 中此参数无数据), 而其相对浓度(即饱和度)却显 示了较大的变化范围, 表层水都处于过饱和状态, 溶解氧饱和度可达 $105 \%$, 而底层水为未饱和状态, 含 量约为 $80 \%$ 左右.

电导率是一个在垂直方向上非常稳定的参数, 只在某些剖面中大约 15-20m 深度处出现微小的降低 趋势，但在其他剖面中却没有这种变化甚至出现相反的趋势，说明电导率本身变化很小，但在不同站点 的垂向变化趋势上却有不同的表现.
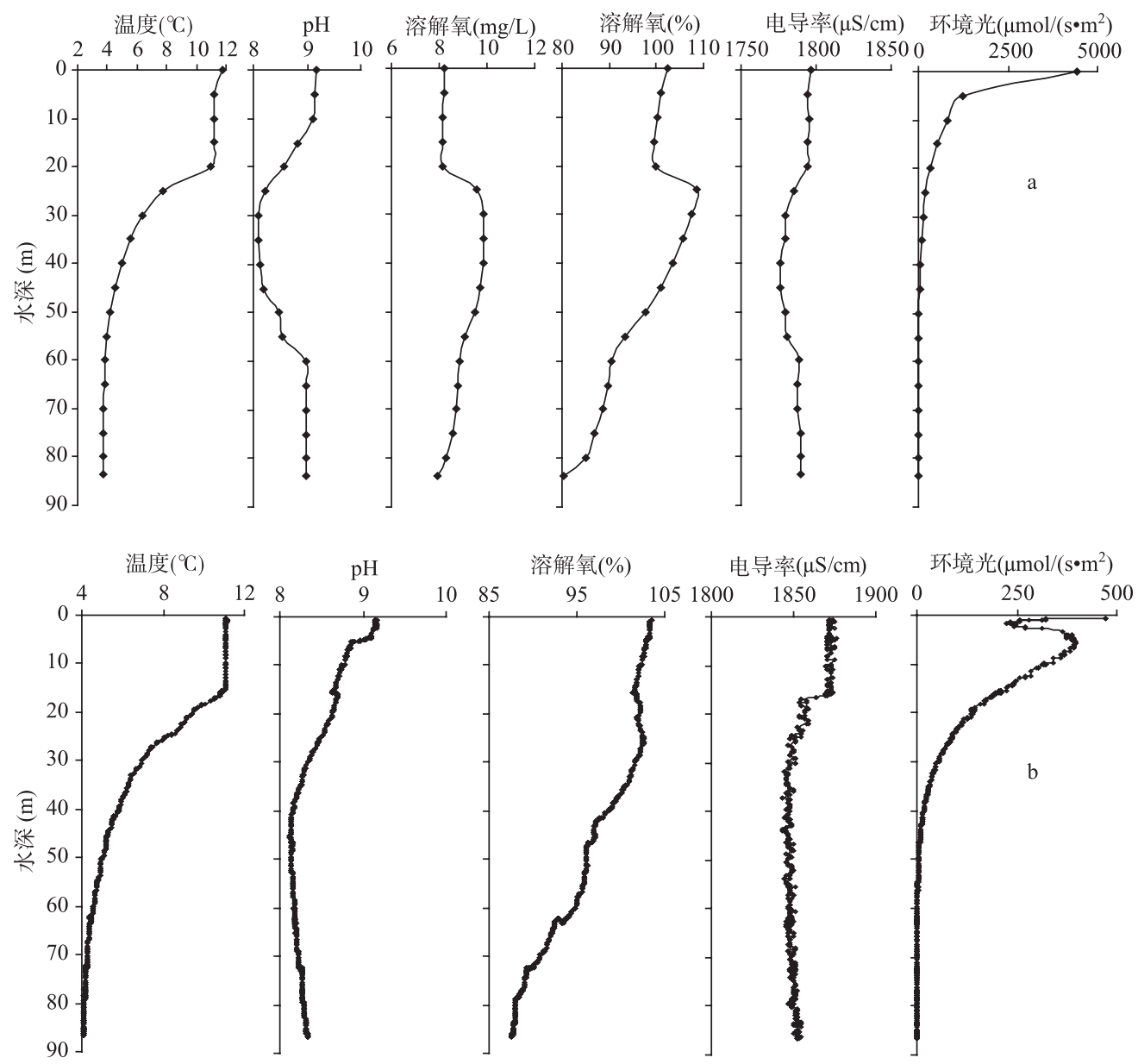

图 3 纳木错水质测量垂直剖面变化(a: 2006-09-19; b: 2007-08-18)

Fig.3 Two typical limnological profiles in Nam Co

环境光参数反映了湖水的透光性, 也就是其透明度. 所有测量剖面 PAR 的变化出现两种变化趋势(图 3). 利用单点测量法得到的结果都显示了非常一致的变化趋势, 即在表层 PAR 值都很高, 然后快速衰减 到 $30 \mathrm{~m}$ 深度附近的 $100 \mu \mathrm{mol} /\left(\mathrm{s} \cdot \mathrm{m}^{2}\right.$ )左右, 之后几乎接近零(图 3a); 而图 3b 所示的利用连续测量法得到的 剖面则显示在大约 4-7m 深度处有一个次高值, 即 PAR 的最高值仍然是在表层, 然后快速下降之后又出 现升高的趋势并在 4-7m 深度处达到一个较高的值, 在此深度之下又迅速衰减至接近零值; PAR 的这种变 化特征在普莫雍错的考察报告中也有报道 ${ }^{[14]}$. 对比 PAR 的这两种变化曲线, 可以认为连续测量法得到的 连续剖面可能更接近湖水的真实状况，而单点测量法则可能由于测量间隔较大而将这一变化细节遗漏. 
图 $3 \mathrm{~b}$ 所显示的 PAR 剖面变化情况是所有连续测量法的典型代表, 所不同的是不同位置的剖面次高值出 现的深度略有差异.

将 5 个水质参数进行对比, 可以发现纳木错深水区的湖水在垂直方向上可以分为 3 层. 根据图 3 所 显示的两个典型剖面，第一层是从表层到大约 18-20m 深度，这一层的湖水除了 PAR 显示了固有的衰减 规律外, 其他参数都很稳定. 温度、 $\mathrm{pH}$ 和电导率都显示了较高的值, 并且水中有丰富的溶解氧和足够的 光照, 提供了适合浮游生物生长的条件. 第二层的垂直范围大约可在 20-60m, 是一个典型的温跃层, 这 一层湖水最显著的特征是温度的快速下降以及 $\mathrm{pH}$ 、溶解氧和电导率的相应变化. 第三层湖水位于 $60 \mathrm{~m}$ 深 度以下，也就是所谓的 “均温层”，温度稳定在整个水柱中最低的 $4^{\circ} \mathrm{C}$ 左右，也没有光线可以到达，形成 了寒冷黑暗的深水层.

\section{4 结论}

湖泊调查是湖泊学和古湖泊学研究最重要也是最基本的工作. 基于对纳木错的考察数据, 对测深数 据和现代湖沼学参数进行了初步的分析, 得到了对纳木错的一些基本认识, 获得以下初步结论:

(1)纳木错水下地形分布结果显示湖泊中部是一个较大的平坦的水下盆地，中心湖区水深超过 $95 \mathrm{~m}$, 因此纳木错是一个高海拔的深水大湖. 详细的水深分布结果为利用深水区湖泊沉积物进行的古湖泊学研 究采样点的选取提供了良好的基础.

(2)与 1970 年代考察相比，在纳木错西北部出现的相对较新的两个小岛屿为过去 30 年来纳木错湖面 上升提供了直接的证据; 对这两个岛屿周围水深数据的进一步深人研究并结合以前地形图数据可以对纳 木错湖面上升的幅度进行半定量研究.

(3)纳木错表层湖水的温度、 $\mathrm{pH}$ 和溶解氧没有显示出明显的空间差异, 其平均值分别为 $11.63^{\circ} \mathrm{C} 、 9.13$ 和 $7.93 \mathrm{mg} / \mathrm{L}$. 然而, 湖泊西部的水与中部相比具有更高的电导率和更低的环境光参数. 从所有测量结果 来看，表层湖水的电导率和环境光分别为 $1839 \mu \mathrm{S} / \mathrm{cm}$ 和 $2582 \mu \mathrm{mol} /\left(\mathrm{s} \cdot \mathrm{m}^{2}\right)$.

(4)纳木错湖水的湖沼学参数垂向变化趋势表明湖水可以分为 3 层, 特别是在深水区. 分别是表层的 变温层、中间的温跃层和底部的均温层，每一层湖水的理化性质具有明显的差异. 对湖水性质的认识将 会有益于对湖泊现代过程的深人研究如浮游生物和底栖生物的发展、湖泊初级生产力以及沉积过程等. 致谢：感谢所有参加 2005-2007 纳木错考察的人员。中国科学院青藏高原研究所纳木错站工作人员对考 察提供了很大的帮助, 德国耶拿大学 Dr. Ernst Krömer 和 Johannes Wallner 完成了部分测深工作, 陆诗阔 博士对水深数据处理提供了帮助, 在此一并表示感谢.

\section{5 参考文献}

[1] 王苏民, 窦鸿身. 中国湖泊志. 北京: 科学出版社, 1998: 1-580.

[2] 王苏民, 张振克. 中国湖泊沉积与环境演变研究的新进展. 科学通报, 1999, 44(6): 579-587.

[3] 王君波, 朱立平. 青藏高原湖泊沉积与环境演变研究: 现状与展望. 地理科学进展, 2005, 24(5): 1-12.

[4] 中国科学院兰州地质研究所, 中国科学院水生生物研究所, 中国科学院微生物研究所等. 青海湖综合考察报告. 北京: 科学出版社, 1979: 1-270.

[5] 关志华, 陈传友, 区裕雄等. 西藏河流与湖泊. 北京: 科学出版社, 1984: 115-215.

[6] Kawashima M, Nishiyama T. Salt concentration and chemical types of lake, river, snow, and hot spring waters from the Tibetan Plateau. Jpn J Limnol, 1989, 50: 93-104.

[7] 李世杰, 郑本兴, 焦克勤. 西昆仑山区湖泊初探. 海洋与湖沼, 1993, 24(1): 37-44.

[8] 沈永平, 徐道明. 西藏安多的湖泊变化与环境. 冰川冻土, 1994, 16(2): 173-180.

[9] 李世杰, 李万春, 夏威岗等. 青藏高原现代湖泊变化与考察初步报告. 湖泊科学, 1998, 10(4): 95-96.

[10] 李万春, 李世杰, 兴培民. 高原咸水湖水面蒸发估算一一兹格塘错为例. 湖泊科学, 2001, 13(3): 227-232.

[11] 陈毅峰, 陈自明, 何德奎等. 藏北色林错流域的水文特征. 湖泊科学, 2001, 13(1): 21-28.

[12] 安芷生, 王 平, 沈 吉等. 青海湖湖底构造及沉积物分布的地球物理勘探研究. 中国科学(D 辑), 2006, 36(4): 332-341. 
[13] Mitamura O, Seike Y, Kondo K et al. First investigation of ultraoligotrophic alpine Lake Puma Yumco in the pre-Himalaya, China. Limnology, 2003, 4: 167-175.

[14] Murakami T, Terai H, Yoshiyama Y et al. The second investigation of Lake Puma Yum Co located in the Southern Tibetan Plateau, China. Limnology, 2007, 8: 331-335.

[15] 鞠建廷, 朱立平, 汪 勇等. 藏南普莫雍错流域水体离子的组成与空间分布及其环境意义初步研究. 湖泊科学, 2008, 20(5): 591-599.

[16] 朱大岗, 孟宪刚, 赵希涛等. 西藏纳木错地区第四纪环境演变. 北京: 地质出版社, 2004: 1-302.

[17] 王 荣, 羊向东, 朱立平. 西藏纳木错过去 200 年来的环境变化. 第四纪研究, 2006, 26(5): 791-798.

[18] 朱立平, 王君波, 林 晓等. 西藏纳木错深水岩芯反映的 8.4ka 以来气候环境变化. 第四纪研究, 2007, 27(4): 588-597.

[19] 李明慧, 朱立平, 康世昌等. 西藏纳木错沉积物中单水方解石的发现及成因分析. 矿物岩石, 2008, 28(1): 1-7.

[20] 李明慧, 康世昌, 朱立平等. 西藏纳木错沉积物单水方解石出现前后的环境变化. 第四纪研究, 2008, 28(4): 601-609.

[21] 吴艳红, 朱立平, 叶庆华等. 纳木错流域近 30 年来湖泊一冰川变化对气候的响应. 地理学报, 2007, 62(3): 301-311.

[22] 邵兆刚, 朱大岗, 孟宪刚等. 青藏高原近 25 年来主要湖泊变迁的特征. 地质通报, 2007, 26(12): 1633-1645.

[23] Zhu DG, Zhao XT, Meng XG et al. Quaternary lake deposits of Nam Co, Tibet, with a discussion of the connection of Nam Co with Ring Co-Jiuru Co. Acta Geologica Sinica, 2002, 76(3): 283-291.

[24] Hammer UT. Saline lake ecosystems of the world. Monographiae biologiae vol 59. Dr W Junk pulishers, Dordrecht, Netherlands, 1986: 616.

[25] 罗 松, 高俊荣. 抚仙湖各个月份的温度剖面. 声学与电子工程, 2000, (1): 35-39.

[26] 关致和, 赵先龙, 于 政等. 应用声速仪对测深仪改正精度的测试. 海洋测绘, 2003, 23(4): 41-43. 